\title{
Planning for sustainable development of tourism in Songkou ancient town
}

\author{
Hong-Jun $\mathrm{Ou}^{\mathrm{a}}$ \\ Department of fine arts and design, Fuzhou University of International Studies and Trade, Fuzhou City, Fujian \\ Province, China
}

\begin{abstract}
This study is aimed to investigate strategies for urban landscape planning and ecotourism development of Songkou Town to present distinctive cultural landscape. Questionnaire is designed in terms of economy, environment and life. Based on results of questionnaire survey, interview theme and outline are developed and designed and individual in-depth interviews are performed. Besides, through comparison with interview emphasis of report forms in related literatures, we intend to propose optimal policies on urban and rural landscape and ecotourism of Songkou town in order to provide a reference for local government and future researchers.
\end{abstract}

\section{Introduction}

Ancient towns have gradually become new travel destinations for modern people because of their special geographical environment, distinctive architecture style and important historical value. Most ancient towns are located beside beautiful mountains and clear waters, as products of mutual integration of natural environment and human development through thousands of years. Along with rapid development of tourism, many ancient towns are seriously destroyed during exploitation. Therefore, with Songkou ancient town as an example, based on analysis of characteristics of ancient town tourism, this paper tries to propose a concept of "eco-culture as the main axis and sustainable development as the idea" to establish new rural tourism criteria of ancient towns.

This paper is mainly divided into three parts to describe and record current cultural landscape planning and sustainable development situations of Songkou ancient town. The first part introduces history and current development of this ancient town. The second part discusses and analyzes cultural landscape cases in progress. The third part puts forward several directions based on planning of sustainable development idea of the ancient town. Finally, the author makes generalization and summarization to propose possible strategies for cultural-ecological tourism and sustainable development of Songkou ancient town.

\section{History and current development of Songkou ancient town}

Songkou, called Songyang in the past, is situated at southwest of Yongtai, upstream of Dazhang River. Historically, it is at the junction of four prefectures and five counties, acting as the distributing centre

\footnotetext{
${ }^{\mathrm{a}}$ Corresponding author : 2968981426@qq.com
} 
of products from Youxi, Dehua, Xianyou, Putian, and etc. By virtue of such geographical advantage, ancient Songkou wharf was once an important location for merchandises from various parts of China. A flourishing ancient town is gradually formed through tourism and business.

Songkou is the only famous Chinese historical and cultural town in Fuzhou. It is also the hometown of Yuangan Zhang, a patriotic ci writer in the Southern Song Dynasty. Songkou ancient town is the political, economic and cultural center and the important transportation hub of southwestern Yongtai. Within the township, there are more than 60 well-preserved folk houses of Ming and Qing dynasties. In various villages of this town, you can find more than one 100 wellpreserved folk houses of Ming and Qing dynasties.

On October 14, 2008, Songkou town was formally named as "famous Chinese historical and cultural town" by State Administration of Cultural Heritage and Ministry of Housing and Urban-Rural Development, and became the third town of Fujian Province and the only one of Fuzhou City that owns this title. For promoting development of ecological and cultural tourism, in 2014, Oustudio of Taiwan was invited to "feel the pulse" of this old and new town.

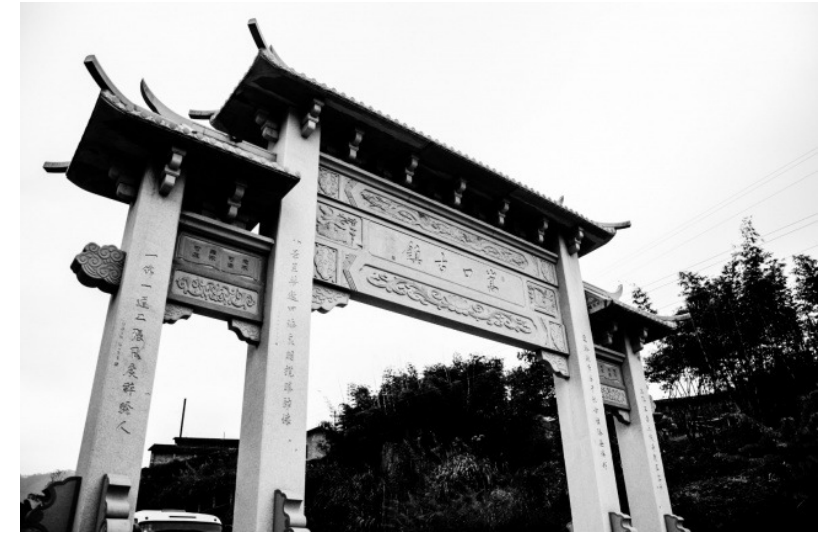

Figure 1. Memorial archway of Songkou town.

\section{Several cases of architectural and cultural landscapes}

\subsection{Crane-shaped road}

As a part of Longkoucuo district, crane-shaped road has been always a popular scenic spot of Songkou due to its unique shape. After establishment at the end of Song Dynasty, multiple parts of this road have been damaged. Some segments have been occupied by surrounding new and old buildings. Some other segments are repaired by descendants, and lose original primitive style due to replacement of cob wall with red bricks and cements. Before renovation, this road was once blocked. In the phase-I tourism line program of Taiwan Oustudio, ${ }^{b}$ crane-shaped road is an important point. During initial repair, Zheng's family of Longkou also paid much attention to re-construction of this road. Consequently, this road becomes the only project of the town that is lead by the government as well as constructed and supervised by local family.

To achieve better effect of cob wall punning during re-construction, many craftsmen who have retired for many years make a lot of attempts under the guidance of Oustudio to test soils of different origins and proportions. The renovated crane-shaped road presents three-segment façade of local conventional low-rise building: lower segment of stone bench-table, middle segment of loess and upper segment of grey- tile roof. The completed crane-shaped road becomes a landscape that

\footnotetext{
${ }^{\mathrm{b}}$ Oustudio was established in 2001, with Guocang Liu as the design director. It is set up in ancient capital of Taiwan-Tainan City.
} 
combines old and new styles and is not bitty any more. Crane-shape road is associated with ancestral directives and culture of Zheng's family of Longkou. Therefore, conceptual design of re-construction should obtain sufficient respect from Zheng's family. Legend of crane-shaped road passed on from generation to generation locally detailedly introduces implication of each structure of this road. ${ }^{\mathrm{c}}$ Finally, the repaired crane-shaped road is also respected during renovation. Meanwhile, people can see the traces of changes in local residential building forms at different historical stages. ${ }^{\mathrm{d}}$

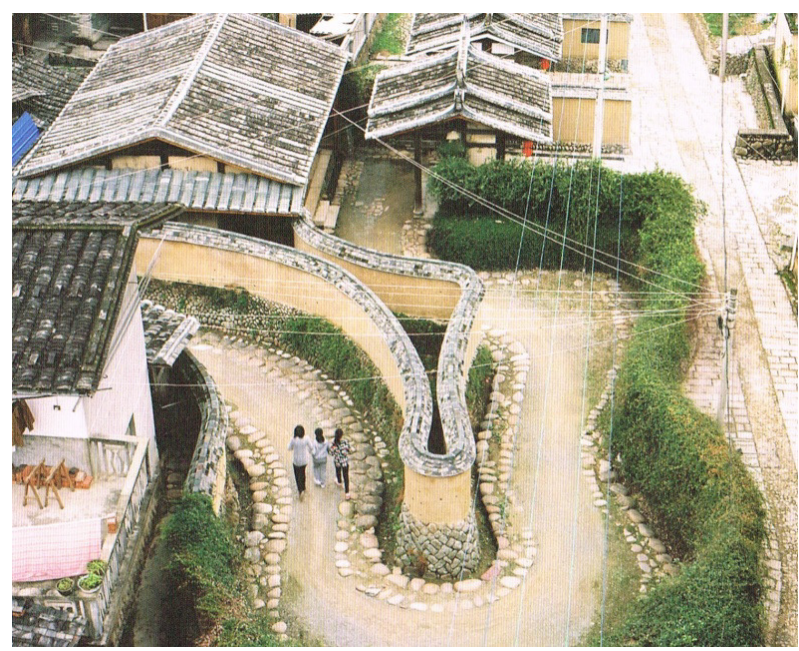

Figure 2. Crane-shaped road ${ }^{\mathrm{e}}$.

\subsection{Movie Temple}

Movie Temple, adjacent to Songkou town government, is the common conception and action of town government, community, local people and Oustudio. It not only functions as the faith center for revitalization of local tradition, but also be endowed with new public functions of new era. It has functions of cinema, auditorium and temple.

Bi-directional experience place is created to achieve cooperation between government and community. In terms of historical development, functions of Movie Temple change with times, which lead to contradiction between government and community in cognition of use of this building in the contemporary era. Movie Temple was once the biggest Dacheng palace in Yongtai County. The main hall faces the north. Since the Cultural Revolution period, this temple has been used as cinema and auditorium. People enter it from the north. The stage is situated in the south. In recent years, people of rural areas generally move out, leading to rising of cities and decline of countryside. Under such context, this cinema and auditorium becomes an idle dangerous building. However, people who have moved out to cities succeed in business, give older generation sufficient economic resources and initiate donation. They plan to dismantle cinema and re-build original temple. The government also has the idea of reviving this place but their direction of plan is different from the community. The government hopes to create a new community public place for current and future uses.

Oustudio utilizes the space plan of "one place, two attributes" to break the deadlock between the government and the community. They transform the base of this dangerous building into a temple

\footnotetext{
${ }^{c}$ Cob wall of the crane-shaped road represents skin layer of crane neck. Therefore, soil road in the center represents esophagus.

${ }^{\mathrm{d}}$ Citation: Homeland (2015)

${ }^{\mathrm{e}}$ It is originally expected to construct pure cob wall. However, current soil ramming technique is not able to achieve such a great bending degree. Therefore, the biggest wall of crane-shaped road is repaired via both bricking and soil paste techniques.
} 
desired by common people and a safe public place expected by the government. New public place functions are set in the new Movie Temple. The second floor inside the bricked façade in the north is used as a meeting space for artistic activities, leisure, playing and singing. ${ }^{\mathrm{f}}$

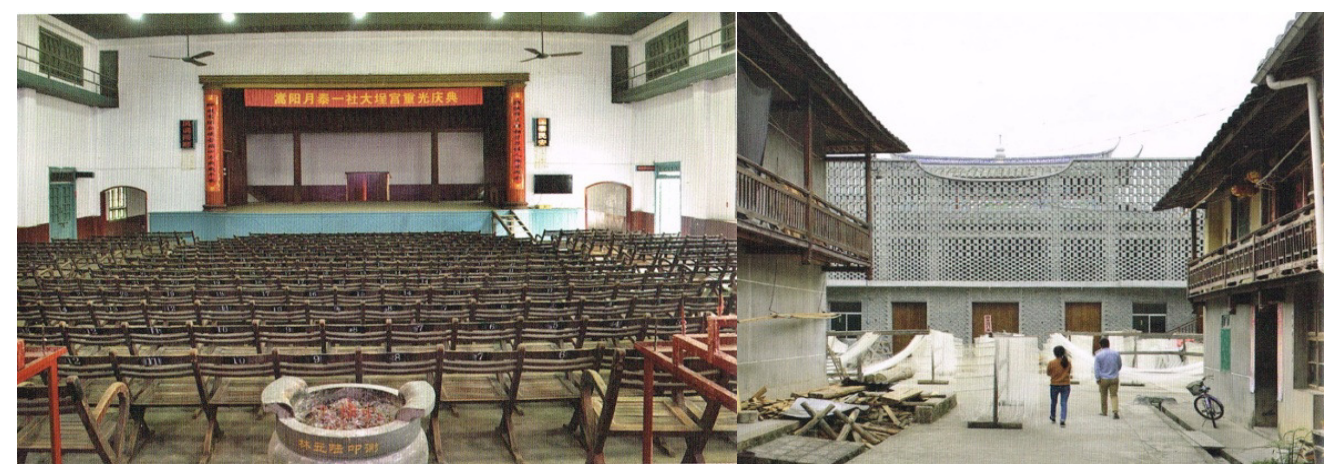

Figure 3. Internal and exterior of the Movie Temple.

\section{Investigation into the idea of sustainable development of Songkou ancient town}

As a Millennium town, Songkou ancient town has rich tourism resources. In consideration of the principle of "no destruction to the natural and human landscape", design of sustainable development is especially significant. With regard to this argument, several planning principles are proposed:

\subsection{Sustainability of tourism product and economy}

To achieve sustainable development of tourist area, the prerequisite is long-term and stable development of economy. On the road of sustainable development, Songkou ancient town should firstly enhance economic benefits. Development and design of tourism product is the key to enhance economic benefits. Under the leadership of Oustudio team, a model point is found on Zhi Street, which leads to the ancient ferry. ${ }^{\mathrm{g}}$ In this composite space, fabrics, wood products, bamboo knitting articles, rattan plaited articles, desserts and local products are gradually dug out. More than six kinds of local agricultural and cultural products are sold in this store.

Besides historical and cultural background, product development of Songkou ancient town should also be introduced with new design ideas to satisfy tourists' thirst for knowledge as well as increase sense of participation and experience. Also, development of various leisure and tourism products should aim to increase tourists' length of stay, promote consumption chain and improve economic income. It is essential to constantly deepen tourism product structure and enhance vital force of products, so as to achieve long-term stable development of tourism economy of this ancient town as well as provide economic guarantee for social sustainability and ecological sustainability.

\subsection{Sustainability of integrative development of ancient town tourism and cultural creative industry}

Tourism is not only a kind of creative and aesthetic economy but also a kind of experience economy. Tourism development of ancient town is based on rich cultural resources and emphasizes outstanding

\footnotetext{
${ }^{\mathrm{f}}$ Citation: Taiwan Architecture (2015)

${ }^{\mathrm{g}}$ For a two-floor store along the Zhi Street of Songkou ancient ferry, Oustudio makes reconstruction and interior decoration. They build a composite space with functions of cafe, accommodation and retail, and name it as "Open Songkou". This store was opened in October, 2015.
} 
originality and feature. Cultural creative industry needs to dig out, integrate and stimulate the spirit of ancient-town cultural tourism resources, in order to motivate the core competitive force, apply such competiveness into development of cultural creative products and create better products for satisfying consumers' demands. Therefore, sustainable development of ancient town tourism must form its characteristic and distinctive industrial layout through integrative and interactive development of human environment, technology and work division of cultural creativity so as to avoid similarity to other ancient towns.

\subsection{Sustainability of ecological culture}

Ecological culture is extension and innovation of culture under certain environment. It mainly advocates harmonious coexistence of human and nature as well as green lifestyle and civilized human morality so that people can actually understand, adore, protect and enjoy the nature. As a kind of emerging culture, ecological culture calls for a conceptual system of harmonious coexistence of human and nature.

To provide theoretical basis of sustainable development, ecological culture that utilizes scientific theory can realize coordinating development of tourists and environment. Ancient town tourism is a carrier of ecological culture. Like Songkou town, all ancient towns bears strong cultural ambience and sufficiently exhibits harmonious coexistence of human and nature. In current tourism bloom, common people more focus on short-term economic benefits due to the effect of market economy. As a consequence, many ancient towns are destroyed.

Ancient town is a special utilizable resource. It has characteristics such as irreplaceability, regeneration, manufacturing, recycle and public. Irrespective of the creator and the preserver, ancient town is historical and cultural heritage and thus considered as common wealth jointly created by human beings. Therefore, in development of ancient town tourism, each tourist and each tourism developer should establish the idea of ecological culture so that tourism resource of ancient town and promotion of sustainable tourism development can have profound significance. $[1,2]$

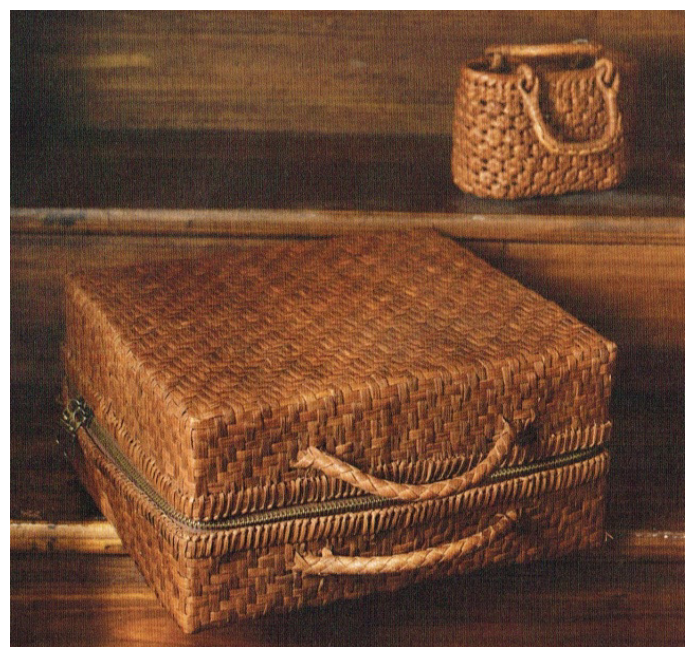

Figure 4. Rattan plaited bags and cases from Yongtai and Songkou.

\section{Conclusion}

To sum up, it is suggested to promote cognition direction of ancient town tourism development and combine with development and construction plan of the government, in order to sufficiently develop the area and achieve sustainable activation of the area. Through research of strategies for developing ecological tourism, conservative and restrained development pattern is recommended. Excessive 
public utilities will compromise original comfort of the space. Original simple and distinctive style can only be restored through subtraction technique.

In addition, this study suggests Songkou ancient town to integrate human resources and local activities. Festival activities can be used to drive legend of local culture so as to achieve win-win situation of local characteristic business and economic industry as well as strengthen centripetal force of local residents. In this process, ecological cultural tourism concept and local organization can be combined to create employment opportunities for grassroots and enhance additional value of ecological tourism industry. It is also recommended to integrate special landscapes and folk activities of Songkou ancient town to form a sustainably-developed eco-museum strategy and concept as well as increase consciousness of local culture and living environment. It is expected to make "the industry, the officials, the academic circle, the researchers" and the local residents jointly participate in the construction, thus to improve quality of local living environment, attract more tourists enthusiastic for ecological tourism, as well as increase quality of ecological tourism "production" enterprise and revenue of residents. "Cultural and ecological museum" will be used as the concept and blueprint for promoting cultural ecological tourism development and local development of Songkou ancient town.

\section{References}

1. Y. Li , Journal of Tourist Market, 79, 77 (2010)

2. H. Zhao and J. Yu, On Economic Problems, 50, 55 (2015) 